\title{
Genotype and phenotype correlations in Iranian patients with hyperinsulinaemic hypoglycaemia
}

Senthil Senniappan ${ }^{1}$, Atefeh Sadeghizadeh ${ }^{2 *}$, Sarah E Flanagan ${ }^{3}$, Sian Ellard ${ }^{3}$, Mahin Hashemipour ${ }^{4}$, Majid Hosseinzadeh ${ }^{5}$, Mansour Salehi ${ }^{6}$ and Khalid Hussain ${ }^{7,8}$

\begin{abstract}
Background: Hyperinsulinaemic hypoglycaemia $(\mathrm{HH})$ is a group of clinically and genetically heterogeneous disorders characterized by unregulated insulin secretion. Abnormalities in nine different genes (ABCC8, KCNJ11, GLUD1, GCK, HADH, SLC16A1, HNF4A, UCP2 and HNF1A) have been reported in HH, the most common being ABCC8 and KCNJ11. We describe the genetic aetiology and phenotype of Iranian patients with $\mathrm{HH}$.

Methods: Retrospective clinical, biochemical and genetic information was collected on 23 patients with biochemically confirmed HH. Mutation analysis was carried out for the ATP-sensitive potassium ( $\mathrm{K}_{\text {ATP }}$ ) channel genes (ABCC8 and KCNJ11), GLUD1, GCK, HADH and HNF4A.

Results: $78 \%$ of the patients were identified to have a genetic cause for $\mathrm{HH} .48 \%$ of patients had mutation in $H A D H$, whilst ABCC8/KCNJ11 mutations were identified in $30 \%$ of patients. Among the diazoxide-responsive patients (18/23), mutations were identified in $72 \%$. These include two novel homozygous $A B C C 8$ mutations. Of the five patients with diazoxide-unresponsive $\mathrm{HH}$, three had homozygous $A B C C 8$ mutation, one had heterozygous $A B C C 8$ mutation inherited from an unaffected father and one had homozygous KCNJ11 mutation. $52 \%$ of children in our cohort were born to consanguineous parents. Patients with $A B C C 8 / K C N J 11$ mutations were noted to be significantly heavier than those with HADH mutation ( $p=0.002$ ). Our results revealed neurodevelopmental deficits in $30 \%$ and epilepsy in $52 \%$ of all patients.

Conclusions: To the best of our knowledge, this is the first study of its kind in Iran. We found disease-causing mutations in $78 \%$ of $\mathrm{HH}$ patients. The predominance of $\mathrm{HADH}$ mutation might be due to a high incidence of consanguineous marriage in this population. Further research involving a larger cohort of $\mathrm{HH}$ patients is required in Iranian population.
\end{abstract}

Keywords: Hyperinsulinaemic hypoglycaemia, HADH (hydroxyacyl-CoA-dehydrogenase), Diazoxide

\section{Background}

Hyperinsulinaemic hypoglycaemia $(\mathrm{HH})$ is a group of clinically and genetically heterogeneous disorders characterized by dysregulation of insulin secretion by pancreatic $\beta$-cells [1]. Early diagnosis and treatment is important to prevent permanent brain damage [2]. $\mathrm{HH}$

\footnotetext{
*Correspondence: a.sadeghizadeh@gmail.com

${ }^{2}$ Department of Pediatrics, Child Growth and Development Research

Center, Isfahan University of Medical Sciences, Isfahan, Iran

Full list of author information is available at the end of the article
}

can be either transient or persistent; transient forms of $\mathrm{HH}$ are usually secondary to conditions such as maternal diabetes mellitus or intra-uterine growth retardation [1]. The incidence of $\mathrm{HH}$ can vary from 1 in 35,000-40,000 in the general population [3] to 1 in 2,500 in some communities with high rates of consanguinity [4].

The clinical presentation can be varied ranging from completely asymptomatic, mild disease to severe disease unresponsive to medication needing surgical intervention [5]. The $\mathrm{HH}$ due to recessive mutations in $A B C C 8 / K C N J 11$ is usually severe and requires high 
concentrations of intravenous glucose to maintain normoglycaemia [5]. Hypoglycemic symptoms may vary from being non-specific (such as poor feeding, lethargy and irritability) to severe (such as apnea, seizures or coma). Macrosomia is a common feature in infants, but not all babies with $\mathrm{HH}$ are macrosomic [6]. There are two histological subtypes of CHI: diffuse and focal [7]. The diffuse form is inherited in an autosomal recessive (or dominant) manner whereas the focal form is sporadic in inheritance. The first line of medical therapy in $\mathrm{HH}$ includes diazoxide, which binds to the intact SUR1 component of the $\mathrm{K}_{\mathrm{ATP}}$ channels and prevents depolarization of the $\beta$-cell membrane and insulin secretion [1].

$\mathrm{HH}$ is caused by mutations in the key genes that are involved in regulation of insulin secretion from the pancreatic $\beta$-cells. So far, mutations in $A B C C 8, K C N J 11$, GLUD1, GCK, HADH, SLC16A1, HNF4A, UCP2 and $H N F 1 A$ have been identified to be involved in the pathogenesis of $\mathrm{HH}[1,8]$. The most common causes of diffuse medically unresponsive $\mathrm{HH}$ are mutations in $A B C C 8$ and KCNJ11. These two genes encode for the SUR1 (sulphonylurea receptor 1 subunit) and Kir6.2 (inward-rectifying potassium channel pore-forming subunit) proteins, respectively which constitute the $\mathrm{K}_{\mathrm{ATP}}$ channel of the pancreatic $\beta$-cell membrane [2].

The inactivating mutations in $A B C C 8 / K C N J 11$ reduce or completely abolish the activity of the $\mathrm{K}_{\mathrm{ATP}}$ channel, leading to unregulated insulin release despite severe hypoglycaemia [9]. The recessive inactivating mutations in $A B C C 8$ and $K C N J 11$ usually cause severe $\mathrm{HH}$, which is unresponsive to medical treatment with diazoxide. The molecular basis of recessive inactivating $A B C C 8$ and KCNJ11 mutations involve defects in $\mathrm{K}_{\text {ATP }}$ channel biogenesis and turnover, channel trafficking from the ER and Golgi apparatus to the plasma membrane and alterations of channels in response to nucleotide regulation and open state frequency [10]. Dominant inactivating mutations in $A B C C 8$ and $K C N J 11$ usually cause $\mathrm{HH}$ with a milder phenotype [11].

Hyperinsulinism-hyperammonaemia syndrome (HI/ $\mathrm{HA}$ ), the second most common form of HH is associated with activating missense mutations in GLUD1, which encodes the mitochondrial matrix enzyme, glutamate dehydrogenase (GDH). Patients present with recurrent symptomatic postprandial hypoglycaemia following protein-rich meals (leucine-sensitive hypoglycaemia) as well as fasting hypoglycaemia accompanied by asymptomatic elevations of plasma ammonia [12]. Mutations in HNF4A, HNF1A and GCK cause maturity-onset diabetes of the young (MODY) as well $\mathrm{HH}[8,13]$.

Mutations in the mitochondrial $H A D H$ gene (encoding the enzyme L-3-hydroxyacyl-coenzyme A dehydrogenase, $\mathrm{HADH}$ ), are a rare cause of $\mathrm{HH}$ [14]. This enzyme catalysis the conversion of L3-hydroxyacyl-CoAs of variable chain length to their corresponding 3-ketoacylCoAs and exerts highest activity to 3-hydroxybutyrylCoA. HADH mutations can lead either to severe neonatal $\mathrm{HH}$ or to mild late onset $\mathrm{HH}$ [15]. All patients reported so far have responded to diazoxide and some had abnormal acylcarnitine metabolites (raised plasma hydroxybutyrylcarnitine and urinary 3-hydroxyglutarate levels). Protein sensitivity has been demonstrated in patients with HADH mutations [16] and this has been confirmed in the HADH knockout mouse [17]. However the precise mechanism of dysregulated insulin secretion in patients with a HADH deficiency is not understood but might involve an interaction between GDH and HADH [17]. Genetic analysis for HADH gene is recommended in patients with diazoxide responsive $\mathrm{HH}$ from consanguineous families, who are negative for mutations in the $\mathrm{K}_{\mathrm{ATP}}$ channels [18].

Although clinical characteristics and genetic etiology of $\mathrm{HH}$ patients have been described in some studies [1921], little is known about $\mathrm{HH}$ in the Iranian population with a high rate of consanguineous marriages [22]. The aim of this study was to investigate genotype/phenotype correlations in a sample of Iranian patients with $\mathrm{HH}$ from Isfahan.

\section{Methods}

In this cross-sectional study, we collected data on the patients who visited the pediatric endocrinology outpatient clinics and the infants who were referred to $\mathrm{Al}$ Zahra Hospital from September 1998 to July 2012. All infants and children were diagnosed with $\mathrm{HH}$ based on clinical and biochemical criteria [2]. Patients with a secondary cause of $\mathrm{HH}$ such as perinatal asphyxia, prematurity, intra-uterine growth restriction, and syndromic forms were excluded. The clinical data included age at presentation, birth weight, medications, neonatal history, epilepsy and neurological deficits, family history, history of hypoglycaemia following protein-rich meals and consanguinity of parents. Serum ammonia level was checked in all patients.

Children were defined as being responsive to diazoxide when (a) feeding with normal frequency and volume (b) able to fast appropriately for age and maintain normal blood glucose levels (c) serum insulin level low or undetectable at the end of the fast (d) appropriate increase in serum fatty acids and ketone bodies at the end of the fast [2]. Diazoxide-unresponsive patients either underwent near total pancreatectomy or were managed with combinations of octreotide and diazoxide along with high calorie feeds.

Written informed consent for genetic tests was obtained from parents of all patients. The study was 
reviewed and approved by the Ethical Committee of Isfahan University of Medical Sciences.

Genomic DNA was extracted from peripheral leukocytes using standard procedures. All exons and intronexon boundaries of $A B C C 8, K C N J 11, H A D H$, GLUD1, HNF4A and GCK genes were amplified by PCR. The products were sequenced using a BigDye Terminator v3.1 Cycle sequencing Kit on an ABI 3730XL Analyzer (Applied Biosystems, Foster City, CA, USA) and sequences were compared with the reference sequence (NM_000525 for KCNJ11, NM_000352.3 for ABCC8, and NM_000162.3 for GCK) using Chromas (V.2.01, Technelysium Pty Ltd, Tewantin QLD, Australia) or Mutation Surveyor software V3.24 (Softgenetics, State College, PA, USA). Mutation testing was done on parental samples when a mutation was identified in the child. If no mutation was identified, testing for a partial/whole gene deletion was undertaken using multiplex ligation-dependent probe amplification (MLPA).

\section{Statistical analysis}

Data are presented as mean \pm standard deviation and frequency. The independent sample $t$ test was used to assess continuous variables between two groups. The Mann-Whitney test was used for data that were not normally distributed. Analyses were performed using SPSS (IL, USA, version 19.0). Significant level was set as $\mathrm{P}<0.05$.

\section{Results}

Twenty-three patients with $\mathrm{HH}$ with age ranging from 1 month to 21 years were included in this study. One patient with achondroplasia and three children with secondary $\mathrm{HH}$ due to intra-uterine growth restriction were excluded. The age at presentation ranged from neonatal period (day 1 of life) to 3 years. Eleven ( $47 \%$ ) of the patients were noted to be symptomatic within the first $48 \mathrm{~h}$ after birth. The most common clinical symptom was seizure $(82 \%)$. All patients except two children were born at full term. The mean birth weight was $3,423 \pm 757 \mathrm{~g}$ (with a range of 1,700-5,000 g). Only five patients (21\%) were macrosomic. Ten ( $43 \%$ ) of patients were female. 12 (52\%) children with $\mathrm{HH}$ were born to consanguineous couples. Two families had two affected children.

A high frequency (30\%) of neurodevelopmental delay was observed in these patients. Furthermore, 12 (52 \%) patients suffered from epilepsy. None of the patients had hyperammonemia.

A total number of 18 (78\%) patients responded to diazoxide. Five diazoxide-unresponsive patients underwent near total pancreatectomy. One of them died at 4 months of age due to thromboembolism in the postoperative period. One other patient, who was managed with combinations of octreotide and diazoxide, died at 3 months of age due to sepsis. Clinical characteristics and gene mutations of these patients were summarized in Table 1.

Disease causing mutations were identified in $78 \%$ of the patients ( $48 \%$ had $H A D H$ mutation, $26 \%$ had $A B C C 8$ and $4 \%$ had KCNJ11 mutation) (Fig. 1). Of the five with diazoxide-unresponsive $\mathrm{HH}$, three had homozygous $A B C C 8$ mutation, one had heterozygous $A B C C 8$ mutation, which was inherited from an unaffected father, and one had homozygous KCNJ11 mutation. All three diazoxide unresponsive patients with homozygous $A B C C 8$ mutation were managed by subtotal pancreatectomy. One of these patients needed insulin due to hyperglycemia in the post-operative period. The other two patients were euglycemic on a small $(5 \mathrm{mg} / \mathrm{kg} / \mathrm{day})$ dose of diazoxide. One patient with a paternally inherited mutation was treated non-surgically with octreotide and diazoxide. One patient with homozygous KCNJ11 mutation was managed by total pancreatectomy.

Interestingly two patients with a novel homozygous intronic $A B C C 8$ mutation were diazoxide responsive and $\mathrm{HH}$ resolved by 4 years of age in one of the two patients. The mechanism of this is not clear.

The same homozygous $H A D H$ mutation was identified in 11 children with diazoxide-responsive $\mathrm{HH}$ [frameshift mutation c.617delA, which is a deletion of an A nucleotide at position 617 and is predicted to result in a premature termination at codon 219 (p.K206fsX14)]. This included two affected siblings in two different families. Eight $(72 \%)$ children with $H A D H$ mutation had a history of hypoglycemia following protein-rich meals, although no formal protein load test was done in these patients.

Infants with $A B C C 8 / K C N J 11$ mutations were heavier at birth in comparison to the patients with $H A D H$ mutation $(4,190 \pm 550 \mathrm{~g}$ vs. $3,255 \pm 318 \mathrm{~g}, \mathrm{P}=0.002)$. The mean age of presentation of patients with a $H A D H$ mutation was 99.1 days in comparison to 1.14 days in patients with $A B C C 8$ mutations; the difference was statistically significant $(\mathrm{P}=0.004)$.

\section{Discussion}

In this study, $78 \%$ of patients with $\mathrm{HH}$ from Isfahan, Iran were noted to have disease-causing mutations. It is very interesting to note that $H A D H$ mutation was the commonest genetic cause in this cohort (48\%) as opposed to the $A B C C 8$ mutations, which was noted only in $26 \%$ of patients. The higher incidence of patients with $H A D H$ mutation accounted for the higher rate of diazoxide responsiveness in this group (78 \%). All diazoxide-unresponsive patients in this series had identifiable mutations (ABCC8/KCNJ11), whilst no mutation was identified in $28 \%$ of diazoxide-responsive patients. 


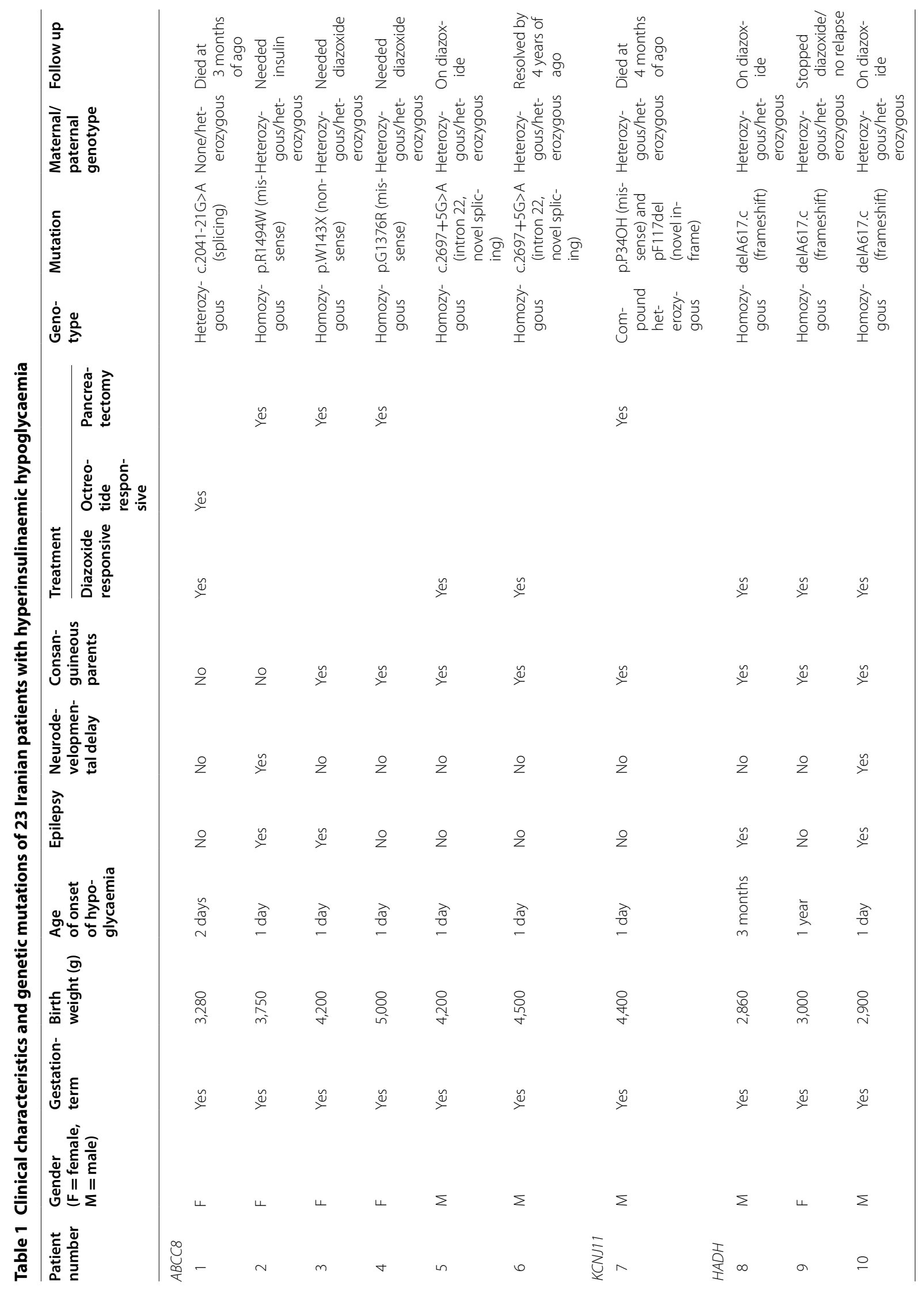




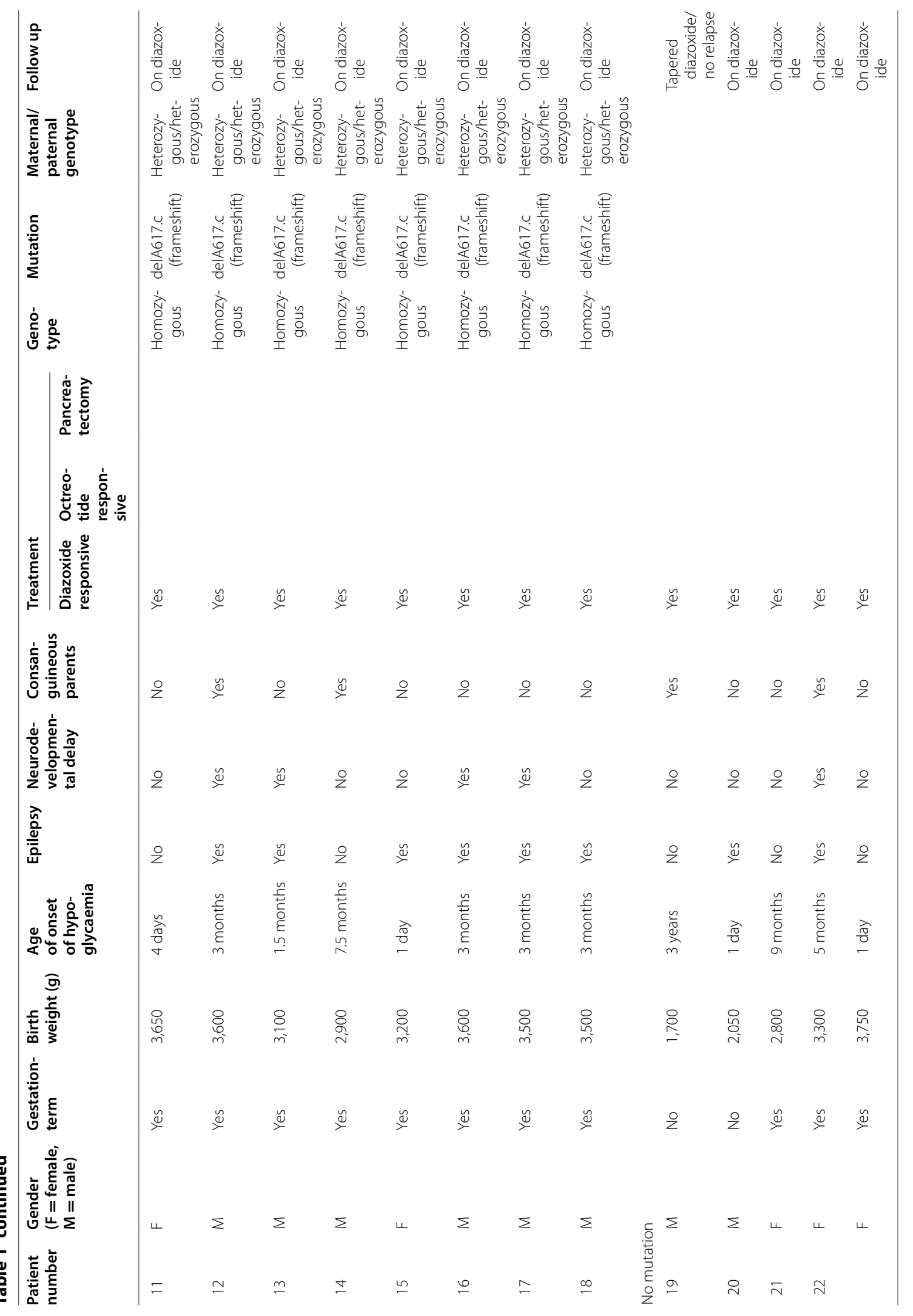




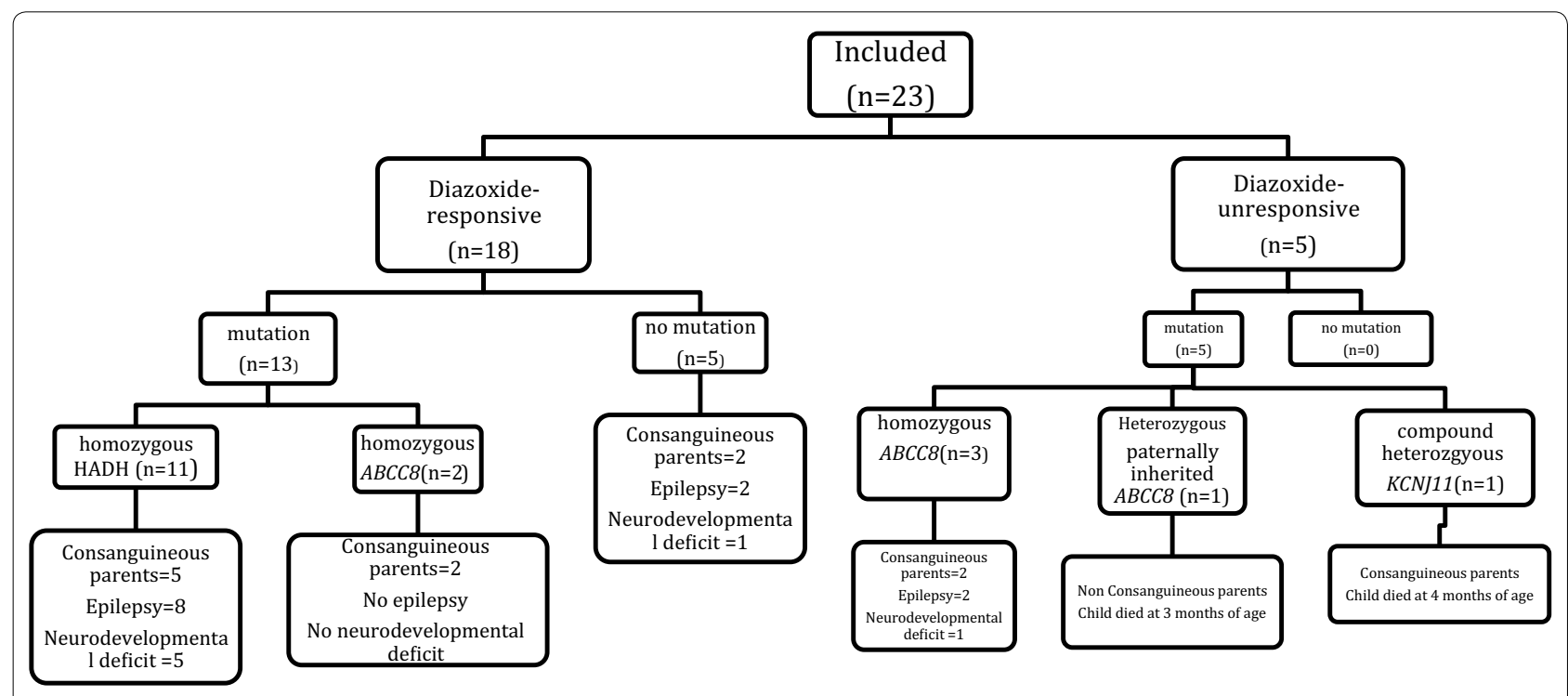

Fig. 1 Summary of the genotype-phenotype correlation and long term outcome.

In contrast to these observations, several other studies suggest a major role of $\mathrm{K}_{\text {ATP }}$ channel in the pathogenesis of patients with $\mathrm{HH}[19,21,23]$. In a large series of 417 patients with $\mathrm{HH}$, mutations were identified in $91 \%$ of diazoxide-unresponsive probands, and in $47 \%$ of diazoxide-responsive patients [20]. However, only 2 cases ( $4 \%$ of diazoxide-responsive probands) were positive for $H A D H$ mutation. In another large series involving 300 patients with $\mathrm{HH}$ [19], mutations were identified in $45.3 \%$ of patients and $A B C C 8 / K C N J 11$ mutations were noted to be the commonest. Among the $22.4 \%$ of patients who had mutations in the diazoxide responsive group, only 3 patients ( $1 \%$ of all cases) had $H A D H$ mutation [19].

In keeping with previous observation [14, 19, 20], all patients with $H A D H$ mutation in this group were diazoxide responsive, whilst the majority of patients $(71 \%)$ with $A B C C 8 / K C N J 11$ mutations were diazoxide-unresponsive. As shown previously, patients with $H A D H$ mutation were diagnosed later and were of normal birth weight in comparison to $A B C C 8$ mutations [19, 24].

The clinical presentation of patients with heterozygous (autosomal dominant) $A B C C 8$ mutations is variable, ranging from mild medically responsive forms to severe early-onset $\mathrm{HH}$ and the vast majority of patients who do not respond to diazoxide have homozygous $A B C C 8$ mutations [20]. We observed that three of the five patients with severe $\mathrm{HH}$ had homozygous $A B C C 8$ mutations. Interestingly a novel homozygous $A B C C 8$ mutation was identified in two patients with a mild form of $\mathrm{HH}$ that resolved completely. The precise mechanism of the course of $\mathrm{HH}$ in these patients is unclear.
Genetic analysis of $H A D H$ is generally suggested in patients with diazoxide responsive $\mathrm{HH}$ from consanguineous families, who are negative for mutations in the $\mathrm{K}_{\text {АTP }}$ channels [18]. The Iranian population like some other populations, has a high level of consanguinity [22]. A higher rate of consanguineous marriages may favor the onset and increased frequency of autosomal recessive diseases in a population [22]. Parental consanguinity was observed in $45 \%(5 / 11)$ of patients with HADH mutation in our cohort. Hence the higher incidence of HADH mutation in our group of patients is very likely related to the higher rate of consanguineous marriages in these families. Also $80 \%(4 / 5)$ of children with homozygous $A B C C 8$ mutation had consanguineous parents.

Our results showed neurodevelopmental deficits in $30 \%$ of the patients and epilepsy in $52 \%$ of all cases. The prevalence of mental retardation and epilepsy was reported to be 31 and $15 \%$, respectively in a group of patients with $\mathrm{HH}$ in Austria [25]. Long-term follow up of 114 patients with $\mathrm{HH}$ showed poor general outcome with a high degree of psychomotor or mental retardation (44\%) or epilepsy (25\%) [26]. Another study from Argentina reported neurological impairment in $38 \%$ of children with $\mathrm{HH}$ [27], whereas a study from Greece which followed up $13 \mathrm{HH}$ patients reported a good neurological outcome without any psychomotor retardation [28]. It is well known that neonatal hypoglycemia is associated with neurodevelopmental complications [29-31].

Our study has several limitations. Firstly it includes a small number of patients from Isfahan, which may not be representative of the whole Iranian population. Secondly the data was collected on a retrospective basis from the 
medical records. Finally, an 18-F DOPA PET/CT scan was not available to differentiate focal from diffuse lesion.

\section{Conclusion}

This study first of its kind from Iran, demonstrates disease-causing mutations in $78 \%$ of $\mathrm{HH}$ patients from Isfahan. Majority of these patients (78 \%) responded to medical therapy with diazoxide. A high rate (48\%) of $H A D H$ mutation is seen in this population that might be attributed to a high rate of consanguineous marriages. Data shows a suboptimal long-term outcome with a high degree of neurodevelopmental deficits and epilepsy in these patients. Further research with a larger number of patients is necessary to identify the mechanism(s) of $\mathrm{HH}$ in Iranian population.

\begin{abstract}
Abbreviations
GCK: glucokinase; GDH: glutamate dehydrogenase; HI/HA: hyperinsulinismhyperammonaemia syndrome; $\mathrm{HH}$ : hyperinsulinaemic hypoglycaemia; $\mathrm{HADH}$ : hydroxyacyl-coenzyme A dehydrogenase; HNF: hepatocyte nuclear factor; MLPA: multiplex ligation-dependent probe amplification; MODY: maturity onset diabetes of the young; PCR: polymerase chain reaction; $K_{\text {ATP: }}$ potassium ATP channel; SUR: sulphonylurea receptor.
\end{abstract}

\section{Authors' contributions}

$\mathrm{AH}, \mathrm{MH}, \mathrm{MH}$ and $\mathrm{MS}$ collected the data and prepared the first draft. SEF and SE carried out the molecular genetic studies. AH performed the statistical analysis. SS and $\mathrm{KH}$ participated in the design of the study and revision of the manuscript. All authors read and approved the final manuscript.

\begin{abstract}
Author details
${ }^{1}$ Alder Hey Children's Hospital, Liverpool, UK. ${ }^{2}$ Department of Pediatrics, Child Growth and Development Research Center, Isfahan University of Medical Sciences, Isfahan, Iran. ${ }^{3}$ Institute Biomedical and Clinical Science, University of Exeter Medical School, Exeter EX2 5DW, UK. ${ }^{4}$ Endocrinology and Metabolism Research Center, Isfahan University of Medical Sciences, Isfahan, Iran. ${ }^{5}$ Medical Genetics Laboratory, Alzahra University Hospital, Isfahan University of Medical Sciences, Isfahan, Iran. ${ }^{6}$ Pediatric Inherited Disease Research Center (PIDRC), Isfahan University of Medical Sciences, Isfahan, Iran. ${ }^{7}$ Developmental Endocrinology Research Group, Clinical and Molecular Genetics Unit, Institute of Child Health, University College London, London, UK. ${ }^{8}$ Department of Paediatric Endocrinology, Great Ormond Street Hospital for Children, London, UK.
\end{abstract}

\section{Acknowledgements}

None.

\section{Compliance with ethical guidelines}

\section{Competing interests}

The authors declare that they have no competing interests.

Received: 29 October 2014 Accepted: 4 August 2015

Published online: 13 August 2015

\section{References}

1. Senniappan S, Shanti B, James C, Hussain K (2012) Hyperinsulinaemic hypoglycaemia: genetic mechanisms, diagnosis and management. J Inherit Metab Dis 35:589-601

2. Senniappan S, Arya VB, Hussain K (2013) The molecular mechanisms, diagnosis and management of congenital hyperinsulinism. Indian J Endocrinol Metab 17:19-30
3. Bruining GJ (1990) Recent advances in Hyperinsulinism and the pathogenesis of diabetes mellitus. Curr Opin Pediatr 2:758-765

4. Mathew PM, Young JM, Abu-Osba YK, Mulhern BD, Hammoudi S, Hamdan JA et al (1988) Persistent neonatal hyperinsulinism. Clin Pediatr (Phila) 27:148-151

5. Aynsley-Green A, Hussain K, Hall J, Saudubray JM, Nihoul-Fekete C, De Lonlay-Debeney P et al (2000) Practical management of hyperinsulinism in infancy. Arch Dis Child Fetal Neonatal Ed 82:F98-F107

6. Pearson ER, Boj SF, Steele AM, Barrett T, Stals K, Shield JP et al (2007) Macrosomia and hyperinsulinaemic hypoglycaemia in patients with heterozygous mutations in the HNF4A gene. PLoS Med 4:e118

7. Rahier J, Guiot Y, Sempoux C (2000) Persistent hyperinsulinaemic hypoglycaemia of infancy: a heterogeneous syndrome unrelated to nesidioblastosis. Arch Dis Child Fetal Neonatal Ed 82:F108-F112

8. Stanescu DE, Hughes N, Kaplan B, Stanley CA, De León DD (2012) Novel presentations of congenital hyperinsulinism due to mutations in the MODY genes: HNF1A and HNF4A. J Clin Endocrinol Metab 97(10):E2026-E2030

9. Kane C, Shepherd RM, Squires PE, Johnson PR, James RF, Milla PJ et al (1996) Loss of functional KATP channels in pancreatic beta-cells causes persistent hyperinsulinemic hypoglycemia of infancy. Nat Med 2:1344-1347

10. Lin YW, MacMullen C, Ganguly A, Stanley CA, Shyng SL (2006) A novel KCNJ11 mutation associated with congenital hyperinsulinism reduces the intrinsic open probability of beta-cell ATP-sensitive potassium channels. J Biol Chem 281:3006-3012

11. Pinney SE, MacMullen C, Becker S, Lin YW, Hanna C, Thornton P et al (2008) Clinical characteristics and biochemical mechanisms of congenital hyperinsulinism associated with dominant KATP channel mutations. J Clin Invest 118:2877-2886

12. Hsu BY, Kelly A, Thornton PS, Greenberg CR, Dilling LA, Stanley CA (2001) Protein-sensitive and fasting hypoglycemia in children with the hyperinsulinism/hyperammonemia syndrome. J Pediatr 138:383-389

13. Kapoor RR, Locke J, Colclough K, Wales J, Conn JJ, Hattersley AT et al (2008) Persistent hyperinsulinemic hypoglycemia and maturity-onset diabetes of the young due to heterozygous HNF4A mutations. Diabetes 57:1659-1663

14. Clayton PT, Eaton S, Aynsley-Green A, Edginton M, Hussain K, Krywawych S et al (2001) Hyperinsulinism in short-chain L-3-hydroxyacyl-CoA dehydrogenase deficiency reveals the importance of beta-oxidation in insulin secretion. J Clin Invest 108:457-465

15. Martins E, Cardoso ML, Rodrigues E, Barbot C, Ramos A, Bennett MJ et al (2011) Short-chain 3-hydroxyacyl-CoA dehydrogenase deficiency: the clinical relevance of an early diagnosis and report of four new cases. J Inherit Metab Dis 34:835-842

16. Kapoor RR, James C, Flanagan SE, Ellard S, Eaton S, Hussain K (2009) 3-Hydroxyacyl-coenzyme A dehydrogenase deficiency and hyperinsulinemic hypoglycemia: characterization of a novel mutation and severe dietary protein sensitivity. J Clin Endocrinol Metab 94:2221-2225

17. Li C, Chen P, Palladino A, Narayan S, Russell LK, Sayed S et al (2010) Mechanism of hyperinsulinism in short-chain 3-hydroxyacyl-CoA dehydrogenase deficiency involves activation of glutamate dehydrogenase. J Biol Chem 285:31806-31818

18. Flanagan SE, Patch AM, Locke JM, Akcay T, Simsek E, Alaei M et al (2011) Genome-wide homozygosity analysis reveals HADH mutations as a common cause of diazoxide-responsive hyperinsulinemic-hypoglycemia in consanguineous pedigrees. J Clin Endocrinol Metab 96:E498-E502

19. Kapoor RR, Flanagan SE, Arya VB, Shield JP, Ellard S, Hussain K (2013) Clinical and molecular characterisation of 300 patients with congenital hyperinsulinism. Eur J Endocrinol 168:557-564

20. Snider KE, Becker S, Boyajian L, Shyng SL, MacMullen C, Hughes N (2013) Genotype and phenotype correlations in 417 children with congenital hyperinsulinism. J Clin Endocrinol Metab 98:E355-E363

21. Faletra F, Athanasakis E, Morgan A, Biarnés X, Fornasier F, Parini R et al (2013) Congenital hyperinsulinism: clinical and molecular analysis of a large Italian cohort. Gene 521:160-165

22. Saadat M, Ansari-Lari M, Farhud DD (2004) Consanguineous marriage in Iran. Ann Hum Biol 31:263-269

23. Park SE, Flanagan SE, Hussain K, Ellard S, Shin CH, Yang SW (2011) Characterization of ABCC 8 and KCNJ11 gene mutations and phenotypes in Korean patients with congenital hyperinsulinism. Eur J Endocrinol 164:919-926 
24. Molven A, Matre GE, Duran M, Wanders RJ, Rishaug U, Njølstad PR et al (2004) Familial hyperinsulinemic hypoglycemia caused by a defect in the SCHAD enzyme of mitochondrial fatty acid oxidation. Diabetes 53:221-227

25. Mercimek-Mahmutoglu S, Rami B, Feucht M, Herle M, Rittinger O, Stoeckler-Ipsiroglu S et al (2008) Long-term follow-up of patients with congenital hyperinsulinism in Austria. J Pediatr Endocrinol Metab 21:523-532

26. Meissner T, Wendel U, Burgard P, Schaetzle S, Mayatepek E (2003) Longterm follow-up of 114 patients with congenital hyperinsulinism. Eur J Endocrinol 149:43-51

27. Cresto JC, Abdenur JP, Bergada I, Martino R (1998) Long-term follow up of persistent hyperinsulinaemic hypoglycaemia of infancy. Arch Dis Child 79:440-444
28. Dacou-Voutetakis C, Psychou F, Maniati-Christidis M (1998) Persistent hyperinsulinemic hypoglycemia of infancy: long-term results. J Pediatr Endocrinol Metab 11(Suppl 1):131-141

29. Duvanel CB, Fawer CL, Cotting J, Hohlfeld P, Matthieu JM (1999) Longterm effects of neonatal hypoglycemia on brain growth and psychomotor development in small-for-gestational-age preterm infants. J Pediatr 134:492-498

30. Rovet JF, Ehrlich RM (1999) The effect of hypoglycemic seizures on cognitive function in children with diabetes: a 7-year prospective study. J Pediatr 134:503-506

31. Avatapalle HB, Banerjee I, Shah S, Pryce M, Nicholson J, Rigby L et al (2013) Abnormal neurodevelopmental outcomes are common in children with transient congenital hyperinsulinism. Front Endocrinol (Lausanne) 4:60
Submit your next manuscript to BioMed Central and take full advantage of:

- Convenient online submission

- Thorough peer review

- No space constraints or color figure charges

- Immediate publication on acceptance

- Inclusion in PubMed, CAS, Scopus and Google Scholar

- Research which is freely available for redistribution

Submit your manuscript at

www.biomedcentral.com/submit 